\title{
As FALHAS NA EMERGÊNCIA DA AUTOCONSCIÊNCIA NA CRIANÇA AUTISTA
}

\author{
Olivia Balster Fiore-Correia* \\ Carolina Lampreia** \\ Flavia Sollero-de-Campos***
}

\section{RESUMO}

Crianças com transtorno autístico apresentam falhas significativas na emergência da autoconsciência reflexiva. O objetivo do presente trabalho é analisar os processos envolvidos nestas falhas através de uma discussão das abordagens naturalista e construtivista no campo da filosofia, da neurociência, da psicologia do desenvolvimento e do transtorno autístico. Conclui-se que a abordagem construtivista permite uma melhor compreensão destas falhas, por considerar que elas advêm de prejuízos inicialmente inatos na capacidade de identificação afetiva destas crianças que prejudicam a interação social e o desenvolvimento da linguagem e, por conseguinte, sua capacidade autorreflexiva.

Palavras-chave: transtorno autístico, desenvolvimento infantil, autoconsciência.

\begin{abstract}
EMERGENCE DEFICIENCIES OF SELF-CONSCIOUSNESS IN THE AUTISTIC CHILD

Autistic children present important deficiencies in the emergence of reflective self-consciousness. The present paper analyzes processes involved in these deficiencies through both naturalistic and constructivist approaches in areas such as Philosophy, Neuroscience, Child Development and Autistic Disorder. It concludes that the constructivist approach allows a better
\end{abstract}

* Mestre e Doutoranda em Psicologia Clínica pela Pontifícia Universidade Católica do Rio de Janeiro (PUC-Rio).

** Doutora em Psicologia Clínica; Professora do Programa de Pós-Graduação e Pesquisa em Psicologia Clínica e do Departamento de Psicologia da Pontifícia Universidade Católica do Rio de Janeiro (PUC-Rio).

*** Doutora em Psicologia Clínica; Professora do Departamento de Psicologia da Pontifícia Universidade Católica do Rio de Janeiro (PUC-Rio). 
understanding of these deficiencies for it considers that they result from an innate inability of affective engagement which hinders social interaction and language development and, therefore, self-reflective competence.

Keywords: autistic disorder, child development, self-consciousness.

\section{INTRODUÇÃO}

O transtorno autístico está inserido dentro dos transtornos globais do desenvolvimento, nos quais os sintomas para o diagnóstico devem ser identificados até os três anos de idade da criança (DSM-IV-TR, 2002). Sua definição envolve prejuízos qualitativos em três áreas principais: interações sociais, com a criança apresentando déficits severos em sua capacidade de iniciar, responder, manter ou estabelecer interaçôes com as pessoas; comunicação, tanto considerando comportamentos comunicativos não-verbais, como gestos e sorrisos, e comportamentos comunicativos verbais, como vocalizações e fala; e comportamento - a criança apresenta comportamentos e interesses restritos e repetitivos.

Embora a tríade seja o que permite o diagnóstico, outros prejuízos podem ser identificados, como falhas severas no sistema sensorial destas crianças, no desenvolvimento do brincar, na capacidade de compreender regras sociais e no desenvolvimento da autoconsciência (Baranek, David, Poe, Stone \& Watson, 2006; Hobson, 2002; Hobson, Chidambi, Lee \& Meyer, 2006), esta considerada por Hobson e colaboradores (2006) como a capacidade de autorreflexividade, ou seja, a habilidade exclusiva da espécie humana de refletir acerca de seus próprios sentimentos e açôes, possibilitando ao ser humano, dentre outras conquistas, o planejamento de seus atos, a reflexão de suas condutas e a compreensão de seus sentimentos.

Ainda que imprescindível para o desenvolvimento humano, a autoconsciência tem sido pouco explorada nos estudos acerca do transtorno autístico, embora o tema seja de relevância fundamental para um melhor entendimento do transtorno e desenvolvimento de formas mais eficazes de tratamento para os seus portadores. $\mathrm{Na}$ realidade, a autoconsciência tem sido estudada predominantemente pela filosofia e pela neurociência como um subtema das análises sobre a consciência, importante área de investigação nestas duas disciplinas. Devido a isto, apenas algumas referências têm sido encontradas até o momento sobre a autoconsciência em sujeitos autistas e elas se opõem ao tratar das falhas do seu aparecimento nestes sujeitos (Frith \& Happé, 1999; Hobson et al., 2006). Isto ocorre porque existem duas perspectivas distintas que falam sobre o tema: 1 - a perspectiva cognitivista, representada pela 
Teoria da Mente, que defende um déficit cognitivo inato e primário aos prejuízos na capacidade de autorreflexividade e 2 - a perspectiva construtivista ${ }^{1}$, que deriva os prejuízos no desenvolvimento da autoconsciência de falhas iniciais nas interações sociais e na construção da linguagem destes sujeitos.

O objetivo do presente artigo é analisar os processos e problemas envolvidos no desenvolvimento da autoconsciência no transtorno autístico segundo uma perspectiva construtivista. Para alcançar tal intento, será necessário apresentar brevemente, em um primeiro momento, as perspectivas cognitivista e construtivista na filosofia, representadas, respectivamente, pelo pensamento de Descartes ([1637] 1996) e Wittgenstein (1958), e uma discussão contemporânea no campo da neurociência, a de Damásio (1995, 2000). Em um segundo momento, as perspectivas cognitivista e construtivista serão apresentadas no campo da psicologia do desenvolvimento para que se compreenda como ocorre o desenvolvimento da autoconsciência em crianças com desenvolvimento típico. Somente então, em um terceiro momento, será possível compreender como ocorrem as falhas no aparecimento da autoconsciência em sujeitos autistas a partir da perspectiva cognitivista, representada pela Teoria da Mente (Frith \& Happé, 1999), e da perspectiva construtivista, representada pelo pensamento de Hobson e colaboradores (2006).

Para levar a cabo esta discussão, um aspecto fundamental, que se refere à perspectiva teórica utilizada, precisa ser considerado. A Teoria da Mente, ao adotar um enfoque determinista, considera apenas a dimensão natural/cognitiva à autoconsciência, enquanto a perspectiva construtivista concebe a autoconsciência como uma construção social e linguística a partir de uma base corporal. Por fim, serão feitas as considerações finais.

Cabe ressaltar que, conforme será visto adiante, ainda que a autoconsciência encontre primórdios no desenvolvimento de sujeitos autistas, a sua capacidade autorreflexiva encontra-se seriamente prejudicada. Por isso, é fundamental se compreender o ponto de vista construtivista. Afinal, se esta visão acredita que a autoconsciência é constituída no seio de interações sociais, como pensar o desenvolvimento da autoconsciência no autismo?

\section{A NoÇÃo de AUTOCONSCIÊNCIA NA FILOSOFIA E NA NEUROCIÊNCIA}

A oposição entre a origem natural dos comportamentos humanos e a construção destes mesmos comportamentos no desenvolvimento humano a partir do convívio social remonta a questões lançadas por pensadores como Descartes ([1637] 1996) e Wittgenstein (1958). Daí a importância de se retomar o pensamento 
original destes filósofos e compreender perspectivas contemporâneas, advindas da neurociência, que podem lançar luz sobre questôes atuais acerca da discussão do desenvolvimento da autoconsciência humana.

A concepção cartesiana de autoconsciência considera que esta é uma capacidade inata que envolve um conhecimento direto, indubitável e incorrigível de nosso mundo interno; em suma, um acesso privilegiado. Como afirma Descartes ([1637] 1996):

examinando atentamente o que eu era [...] reconheci que eu era uma substância, cuja essência ou natureza é pensar, e que, para existir, não necessita de nenhum lugar nem depende de coisa alguma material. De sorte que este eu, isto é, a alma pela qual sou o que sou, é inteiramente distinta do corpo, e até mais fácil de conhecer que ele (Descartes, [1637] 1996: 38-39; grifo nosso).

Isso significa que cada pessoa vê, ouve, experimenta alegria e tristeza e usa sentenças como "vejo azul", "tenho dor de dente" para descrever seu estado interno, da mesma maneira que descreve sobre como os outros estão - "ele vê azul", "ele tem dor de dente". As expressões psicológicas são concebidas como nomes de objetos, estados, eventos ou processos internos. Isso parece ser possível porque a pessoa é autoconsciente, consciente das experiências de seu self, algo situado no corpo. Concebida desta maneira, a consciência do selfé uma forma de percepção ou "sentido interno", envolve uma introspeç̧ão. E nossas observações daquilo que ocorre em nosso self são privilegiadas, tendo em vista que o "interno" só é diretamente acessível ao self. Em suma, segundo esta perspectiva, nossas verbalizaçóes de sentenças psicológicas na primeira pessoa parecem ser relatos de como as coisas estão conosco, descrições de eventos "internos" que observamos em foro interno (Hacker, 2007).

Segundo a perspectiva construtivista de Wittgenstein (1958), eminente representante da vertente pragmática da filosofia da linguagem, esta visão é enganadora. Não é que não haja tal coisa como observar nossos próprios estados mentais, descrever nossas experiências e relatá-las. Certamente há tal coisa como autoconhecimento e autoconsciência; mas não consiste de um conjunto de relatos e descrições de nossas sensações, percepções, pensamentos e sentimentos. Descrevemos nosso estado mental, mas isso é um jogo de linguagem diferente que não deve ser assimilado ao jogo de linguagem referente à descrição de objetos externos e comportamentos de outras pessoas. A confusão resulta de uma não-compreensão, por parte dos filósofos, da função do "eu" nas sentenças na primeira pessoa. Por conceberem erradamente a gramática dos verbos psicológicos e epistêmicos, 
construíram uma falsa imagem do que chamam de "autoconsciência". Para Wittgenstein, as afirmaçōes na primeira pessoa funcionam como declaraçôes e não como descriçôes de eventos internos. Por exemplo, a criança se machuca e grita, e nós a ensinamos a substituir seus gritos pela verbalização "dói" ou "tenho dor". Neste caso, a verbalização de dor não se apoia em uma introspecção. Ela é, como o grito, uma expressão ou declaração de dor e não uma afirmação cognitiva ou epistêmica (Hacker, 2007; Lampreia, 1992). Contudo, deve ser observado que ela é uma declaração aprendida no seio de práticas sociais. Consequentemente, a autoconsciência deve ser concebida como uma construção social que se dá pela linguagem.

No campo das neurociências, vários neurocientistas (Edelman, 1992; Penrose, 1999) têm se dedicado ao estudo e a propostas de "teorias da consciência" (Sollero-de-Campos, 2000; Sollero-de-Campos, Winograd \& Landeira-Fernandez, 2007). No que diz respeito ao presente artigo, consideramos a proposta de António Damásio $(1995,2000)$ como a mais pertinente por propor, de maneira consistente, uma teoria da construção de um self a começar como individualidade biológica até chegar a uma autoconsciência humana plena, na e pela linguagem. Ele coloca as bases do self na própria existência de cada indivíduo biológico. Em $O$ erro de Descartes (Damásio, 1995), o autor propõe que vários tipos de raciocínio prático e social dependeriam de nossa capacidade de experimentar sensações e sentimentos. E em $O$ mistério da consciência (Damásio, 2000) pergunta o que tornaria possível sentirmos que nossas experiências e nossos pensamentos nos pertencem - como temos o "sentimento de si”, ou a autoconsciência. De acordo com Damásio (1995), a base das capacidades de consciência e self deve ser encontrada nas emoções - as primárias ligadas ao sistema límbico e as secundárias, ou aprendidas, resultantes da integração entre o córtex frontal e o sistema límbico. Uma falha nesta integração levaria a uma incapacidade de desenvolver emoçôes secundárias, ou sentimentos. Poderia haver autoconsciência, mas precária e insuficiente para manter um relacionamento social adequado aos padróes da cultura.

Damásio propõe vários tipos de consciências, assim como uma hierarquia de selves. A consciência se dá em graus ou etapas que vão da não-consciência - coma, anestesia profunda, sono sem sonhos - até a consciência moral plenamente linguística em humanos. Ela começa quando os cérebros adquirem o poder de contar uma história sem palavras e os estados do organismo vivo estão continuamente sendo alterados por encontros com objetos ou eventos. A consciência emerge quando essa história primordial - a história de um objeto alterando de forma causal o estado do corpo - pode ser contada usando o vocabulário universal não-verbal dos sinais corporais. 
Os vários tipos de consciência incluem, segundo Damásio (2000), a consciência central, a consciência ampliada e a consciência reflexiva. A primeira é a base para a existência da segunda, que possui vários níveis ou graus e fornece um complexo sentido de self e memórias permanentes. A consciência ampliada "em seu ápice [...] é exclusivamente humana” (Damásio, 2000: 251). Ela é "a capacidade de estar consciente de uma gama enorme de entidades e de eventos, ou seja, a capacidade de gerar um senso de perspectiva individual, de propriedade e da condição de agente sobre uma gama de conhecimentos maior que a abrangida pela consciência central" (Damásio, 2000: 254). Como a consciência ampliada é muito mais complexa que a central, ela viabiliza as formas de consciência reflexiva. Esta última seria basicamente a capacidade de pensar sobre suas próprias experiências conscientes por si mesmas. É o ápice da hierarquia, característica dos humanos.

A noção de self de Damásio (1995) vai da individualidade biológica até a individualidade mais complexa humana, a partir da linguagem. O selfsurge a partir da consciência, é um sentimento que aparece desde a coisa mais simples que é o organismo ser modificado pelo encontro com um objeto percebido, lembrado ou imaginado em graus crescentes de complexidade cerebral. A hierarquia de selves proposta por Damásio (2000) envolve um proto-self, um selfcentral e um self autobiográfico. O primeiro é o mais simples e não-consciente. Envolve um conjunto coerente de padrôes neurais que mapeia o estado do organismo; é o precedente biológico do self. $\mathrm{O}$ self central baseia-se na consciência central e mapeia o proto-self. É o primeiro nível onde aparece a consciência. Está distribuído por todo o corpo, envolve a experiência imediata e é recriado a partir de sincronizações de sistemas neurais próximos. Finalmente, o self autobiográfico que resulta da consciência ampliada. Pode ser pré-linguístico - presente em cães e macacos - ou linguístico com expansão da memória de longo prazo. Em suma, para Damásio (2000), os tipos de consciência e self exclusivamente humanos são a consciência ampliada em seu ápice, a consciência reflexiva, a consciência moral e o self autobiográfico linguístico.

A autoconsciência é tratada muito ligeiramente por Damásio. Envolve um sentimento de si, mas não é uma consciência de si ou self. Começa através da capacidade do cérebro de gerar uma imagem "do organismo no ato de perceber e responder a um objeto" (Damásio, 1995: 248). Consiste, inicialmente, em uma narrativa sem linguagem ancorada "nos instrumentos representacionais dos sistemas sensorial e motor no espaço e no tempo" (Damásio, 1995: 249) e não ocorre como um "tudo ou nada". Mas a autoconsciência, que pode se dar sob uma forma imagética, isto é, não-verbal, se desdobra na plena autoconsciência humana - na e pela linguagem. Consideramos que esta concepção poderia abrir caminho para 
o estudo da existência da autoconsciência em pessoas diagnosticadas no espectro autista.

\section{EMERGÊNCIA DA AUTOCONSCIÊNCIA NO DESENVOLVIMENTO INFANTIL TÍPICO}

Considerando o campo da psicologia do desenvolvimento, a oposição entre as visões naturalista e construtivista permanece. Oriundas de diferentes formas de pensar, conforme visto, estas perspectivas apresentam modos distintos de compreender a origem e o aparecimento da autoconsciência no desenvolvimento infantil. Deste modo, é imprescindível a compreensão de como estas posições abordam a questão da autoconsciência no desenvolvimento infantil típico para que em seguida seja possível expandir este conhecimento para o entendimento do fenômeno no desenvolvimento de crianças autistas.

Sendo assim, na área da psicologia do desenvolvimento, uma versão contemporânea da visão cartesiana de mente e autoconsciência está representada pela Teoria da Mente. Segundo esta perspectiva, ter uma teoria da mente significa ser capaz de atribuir estados mentais - crenças, desejos, intenções, sentimentos, etc. - aos outros e a si próprio. Ou seja, as habilidades para atribuir estados mentais a si mesmo e aos outros estariam relacionadas. Neste caso, segundo Frith \& Happé (1999), importantes representantes desta perspectiva, um mecanismo neurocognitivo inato específico subjacente de teoria da mente seria vital para o desenvolvimento da autoconsciência. De acordo com essas autoras, quando as crianças são capazes de relatar seus próprios estados mentais, elas também são capazes de relatar estados mentais dos outros e, quando não são capazes de relatar e compreender estados psicológicos dos outros, também não podem relatar seus próprios estados mentais. Do ponto de vista cognitivo, Frith \& Happé (1999) argumentam que as atribuições de pensamentos aos outros e a si mesmo compartilham a mesma capacidade de metarrepresentar, ou representação de segunda ordem ${ }^{2}$, embora pareçam ser diferentes por considerarem que os próprios estados mentais não precisam ser inferidos através da observação como os dos outros e terem menor probabilidade de estarem errados.

A perspectiva construtivista oferece uma posição distinta acerca do desenvolvimento infantil típico (Lampreia, 2008) e do aparecimento da autoconsciência. Opondo-se a uma visão cartesiana e determinista, esta abordagem considera que a autoconsciência não se origina de um mecanismo neurocognitivo programado para ser ativado em uma idade determinada. Ao contrário, a autoconsciência não é programada, ela se desenvolve inicialmente ao longo das trocas afetivas 
e sociais entre sujeitos, ocorridas desde o primeiro respirar de recém-nascidos, e as suas mães ${ }^{3}$, e posteriormente pela linguagem. Nesta construção, existem precursores que dão condições para que a autoconsciência possa emergir no desenvolvimento infantil típico. Estes precursores são o desenvolvimento do próprio self da criança, visto que é ele que a capacita perceber-se inicialmente diferente dos demais para, então, se tornar objeto de análise. Contudo, o próprio self também tem os seus precursores. Ele se desenvolve a partir de um processo que depende das trocas afetivas entre o bebê e a sua mãe, primeiramente em um nível físico, até poder alcançar um nível reflexivo. Stern (1992) e Hobson (2002) são autores que têm se dedicado à compreensão dos processos interacionais do desenvolvimento humano típico e defendem que são as interações afetivas que possibilitam a construção inicial de um self corporal e posteriormente de um self subjetivo e um self verbal, dando condições para que a autoconsciência possa emergir. Hobson (2002; Hobson et al., 2006; Lee \& Hobson, 1994; 1998) também estende os seus estudos para compreensão do fenômeno em sujeitos autistas, como será visto adiante.

$\mathrm{O}$ início do processo que permite a emergência da autoconsciência estaria naquilo que Hobson (2002) define como a capacidade inata do recém-nascido de ser sensível e responsivo às atitudes afetivas das pessoas e expressivo em relação ao próprio afeto. Isto caracterizaria o processo de identificação definido pela propensão inata do ser humano a registrar e assimilar as atitudes afetivas do outro, que são expressas corporalmente e percebidas através de seus comportamentos aparentes (Hobson et al., 2006), possibilitando que os recém-nascidos e suas mães se engajem em trocas afetivas recíprocas.

Alguns comportamentos iniciais do recém-nascido podem embasar esta teoria. Stern (1992) analisa a capacidade do bebê de sintonizar os seus movimentos com a entonação e cadência da voz dos adultos, quando os mesmos apresentam vocalizações pausadas e exageradas. Brazelton e Cramer (1990) defendem que recém-nascidos buscam o contato com a mãe através dos seus sentidos, como olhar para o rosto dela ou movimentar a cabeça em direção à voz materna, e Meltzoff e Moore (1998) observam a capacidade do recém-nascido de reproduzir os comportamentos de sua mãe através de mímicas neonatais.

Segundo Hobson e colaboradores (2006), somente através da identificação um ser humano é capaz de conectar-se afetivamente com o outro. A partir desta conexão e do estabelecimento de trocas afetivas recíprocas, o bebê passa a, inicialmente, distinguir os contornos físicos e sensórios entre o seu eu e os outros, formando um self corporal, para, mais tarde, poder perceber que esta distinção ocorre também em relação às suas orientações subjetivas, caracterizando o seu self subjetivo. 
O raciocínio de Stern (1992) permite uma melhor elucidação deste argumento. $\mathrm{O}$ autor defende que os sete primeiros meses de vida do bebê são caracterizados pelo desenvolvimento de um self corporal através da organização emergente e em seguida nuclear do self em relação aos outros selves. Esta organização corporal ocorre a partir das experiências afetivas compartilhadas entre o bebê e os outros, visto que as suas experiências de integração corporal dependem da expressão de seu afeto e das reações afetivas de sua mãe a ele. Além disso, esta organização é possibilitada pela capacidade inata do organismo humano de traduzir uma modalidade sensorial para outra, denominada de percepção amodal. Ela permite que os estímulos vindos de diferentes modalidades sensoriais do bebê, como o tato, a audição e a visão, sejam traduzidos como um estímulo integrado, o que dá ao bebê um senso de organização de suas experiências imediatas.

Stern (1992) também propõe o conceito de afetos de vitalidade, definidos como a qualidade sentida pelo bebê de alguma ação de seus cuidadores sobre ele. Assim, o bebê é capaz de sentir as sutilezas das interações, como a intensidade de um toque e a duração de uma vocalização da mãe. Estes níveis sutis de percepção também são capazes de ajudá-lo a experienciar um senso de integração do eu, à medida que eles dão continência às experiências vivenciadas pelo bebê $\hat{e}^{5}$ Deste modo, o processo de identificação, aliado aos processos de integração sensorial do bebê, possibilita que ele experimente uma certa organização de seu próprio corpo a partir do momento em que passa a ter uma percepção global de suas experiências. Com isso, pode desenvolver uma certa integração experiencial, que ocorre através de quatro autoexperiências básicas: a autoagência (autoria das próprias açôes), a autocoerência (senso de ser um todo físico não fragmentado), a autoafetividade (experienciar qualidades internas padronizadas de afetos e sentimentos) e a autohistória (senso de continuidade).

Porém, nestes primeiros meses, é fácil perceber que os contornos que separam o self do bebê dos outros selves estão relacionados aos seus aspectos corporais. Somente mais tarde, estes contornos passam a abarcar outras experiências, ligadas aos desejos, necessidades e intenções das pessoas. Apenas neste momento, há o alcance da própria distinção entre um self e os outros selves subjetivos, marcados pelo reconhecimento pelo bebê de que ele tem estados mentais diferentes dos estados mentais dos outros, mas que são compartilháveis. De acordo com Stern (1992), isto ocorre a partir dos sete meses de vida do bebê, quando ele passa a compreender que não só os comportamentos manifestos e as sensações diretas que marcam o eu e o outro nucleares podem ser compartilhados, mas que as experiências subjetivas também podem sê-lo, através de três modos distintos. Um deles é o da atenção compartilhada ou interatencionalidade, no qual o bebê, 
através de gestos, compartilha a sua atenção por um objeto e/ou evento com o adulto e/ou vice-versa. O outro modo é o da interintencionalidade, no qual o bebê compartilha as suas intenções com o adulto e tenta se comunicar com ele seja por meio de gestos, posturas e/ou vocalizações não-verbais. E o terceiro modo é o da interafetividade, no qual o bebê compartilha os seus estados afetivos com o adulto. A interafetividade pode ser melhor compreendida através da sintonia afetiva, que se desenvolve entre os nove e quinze meses de vida do bebê. Para Stern (1992), a sintonia afetiva é concebida como o modo de um indivíduo expressar a qualidade de um estado afetivo compartilhado sem imitar a exata expressão comportamental utilizada pelo seu parceiro de interação. Por exemplo, a mãe falar com o bebê usando um tom suave e o bebê corresponder através de movimentos suaves dirigidos a ela. Isto permite tanto uma verdadeira intersubjetividade como também a noção por parte da criança de seus próprios sentimentos e açôes.

E, ao ser capaz disto, a criança está apta a desenvolver o seu self verbal, caracterizando-se, a partir dos quinze meses de idade, a capacidade (da criança) de se relacionar com os outros não apenas através de suas experiências afetivas imediatas, mas também através de um nível abstrato e mais impessoal da linguagem dado pelos significados compartilhados de seu grupo social. É neste momento que ela começa a desenvolver a sua capacidade simbólica, de fala, e de tornar o próprio eu objeto de reflexão. Vejamos como isto ocorre voltando ao raciocínio de Hobson (2002).

Segundo Hobson (2002), a partir dos nove meses de idade a criança expande a sua identificação, passando a se identificar com os comportamentos do adulto relacionados aos objetos e eventos do mundo. Se, nos meses anteriores, a criança estava interessada e era responsiva apenas às pessoas em si, a partir desta idade ela se torna interessada e responsiva ao que estas pessoas fazem com as coisas e como se sentem com relação a elas. Deste modo, a criança passa a estar identificada aos outros de tal maneira que é afetada pela reação deles às coisas. Ela descobre que o mundo tem significados devido àquilo que as pessoas sentem ou fazem com ele. Desta maneira, ela descobre que as pessoas têm modos distintos de sentir e se relacionar com as coisas à sua volta e também perspectivas distintas ao se relacionarem com estes eventos. Isto permite que a criança passe a considerar que as pessoas apresentam perspectivas e estados mentais próprios e que ela própria também os tem. É neste período que uma nova consciência de si e dos outros surge no desenvolvimento infantil típico. E é por volta desta fase que as crianças estão envolvidas em imitar os adultos, trazer objetos para mostrar aos outros a fim de compartilhar experiências com eles - e apontam com facilidade para pedir algo 
fora de seu alcance. É neste período também que a criança apresenta um comportamento conhecido como referenciação social (Hobson, 2002), que faz com que reaja a uma situação conforme o adulto responde emocionalmente a ela, como, por exemplo, a criança se recusar a brincar com um brinquedo de seu interesse porque a sua mãe mostrou-se assustada perante ele.

Contudo, é fácil notar que todos estes comportamentos ocorrem diante das experiências vivenciadas momento a momento pela criança. Por isso, até este período, a criança não é capaz de refletir sobre um comportamento ou sobre como se sentiu em determinada situação. Ela apenas adota e assume as atitudes dos outros em interações imediatas. A criança ainda não possui, portanto, autoconsciência.

De acordo com Hobson (2002), a autoconsciência só começa a aparecer a partir do segundo ano de vida das crianças, quando elas se tornam capazes de experienciar que são seres com orientações subjetivas próprias, que as pessoas ao seu redor também o são e que estas orientações não precisam estar baseadas em situaçōes imediatas e concretas. Deste modo, as crianças deixam de reagir às perspectivas do outro dadas apenas através de suas expressōes corporais e comportamentos imediatos, passam também a compreender que perspectivas são essas. É a partir do momento em que esta nova compreensão surge que as crianças podem considerar a sua própria subjetividade como objeto de análise e reflexão. Eis, então, que a autoconsciência pode emergir e ser identificada por Hobson (2002) e Hobson e colaboradores (2006) através de três principais comportamentos: o uso adequado dos pronomes pessoais, como o "eu" e o "você"; o aparecimento de emoções sociais, como o orgulho, a culpa e o embaraço, chamadas assim para caracterizar a interiorização, por parte de um indivíduo, das percepções e avaliações que os outros têm a seu respeito (Hobson et al., 2006); e o fomento do jogo simbólico, considerado por Leslie (1987) como a capacidade da criança de utilizar um objeto ou evento como se fosse outra coisa.

A razão dada por Hobson (2002) e Hobson e colaboradores (2006) para que a autoconsciência seja identificada através destes comportamentos repousa no fato de eles demonstrarem a capacidade da criança em experienciar que ela é um self e que os outros também são selves, tanto em suas dimensões corporais, quanto em sua capacidade de ter sentimentos, intenções e necessidades que a distinguem dos demais. Somente a partir disso, a criança é capaz de trocar perspectivas com as pessoas, compreendendo a intenção do outro ao utilizar tais pronomes, para, então, assumir as palavras ditas pelo outro como próprias, desenvolvendo o uso dos pronomes pessoais, apropriar-se da avaliação dos outros para autoavaliar-se através das emoçôes sociais e utilizar significados próprios separados de sua percepção dos objetos em jogos simbólicos. 
Deste modo, a autoconsciência reflexiva depende do compartilhar afetos advindo das trocas sociais entre os indivíduos e dos significados que são compartilhados através da linguagem. Somente quando um indivíduo pode compartilhar afetos com o outro, ele se torna capaz de vivenciar uma experiência integradora de self. Esta integração dá condiçōes para que o indivíduo compreenda que ele apresenta orientações subjetivas, assim como os outros também as têm, e que estas orientações podem ser compartilhadas tanto afetivamente quanto através dos significados construídos através da linguagem. Isto possibilita ao próprio self ser objeto de reflexão para si próprio.

Em síntese, segundo a visão construtivista, a experiência da autoconsciência só pode ser desenvolvida a partir de um nível pré-reflexivo de interações afetivas recíprocas, no qual as experiências corporais de integração permitem um desenvolvimento incipiente de self até atingir um nível reflexivo, através do alcance de formas mais complexas de percepção do self que permitem a emergência da autoconsciência. Em todo este percurso, o aspecto social e a linguagem ocupam papel primordial na construção do sujeito e de suas aptidões exclusivamente humanas, nas quais aqui se destaca a autoconsciência reflexiva.

Contudo, se este é o processo encontrado ao longo do desenvolvimento infantil típico, cabe perguntar-se a respeito do desenvolvimento da autoconsciência em crianças autistas, nas quais há falhas severas no relacionamento interpessoal e na construção da linguagem (Hobson, 2002).

\section{As FALHAS DA EMERGÊNCIA DA AUTOCONSCIÊNCIA NO DESENVOLVIMENTO DA CRIANÇA AUTISTA}

Após a compreensão da origem da autoconsciência na perspectiva da Teoria da Mente e a compreensão de como ocorre o seu desenvolvimento segundo a visão construtivista, é possível o entendimento das falhas no aparecimento da autoconsciência no desenvolvimento da criança autista e como as diferentes abordagens lidam com a questão. Entrementes, é necessário descrever o transtorno com mais acuidade.

Levando-se em consideração a tríade de prejuízos que identifica o transtorno autístico nas áreas das interações sociais, comunicação e comportamento, autistas apresentam prejuízos qualitativos no relacionamento social com o outro, apresentando ausência na participação de jogos sociais, falta de percepção dos sentimentos dos outros, falhas no desenvolvimento de relaçôes recíprocas com adultos e pares, dentre outros. Além disso, apresentam prejuízos qualitativos na 
comunicação não-verbal, apresentando déficits no contato ocular, expressões faciais, gestos comunicativos e fala funcional. A fala, quando existente, é ecolálica ou sem expressões afetivas; o sujeito não a utiliza para fins comunicativos. Por fim, os prejuízos qualitativos no comportamento referem-se aos movimentos corporais estereotipados, preocupação persistente com partes de objetos, ausência de jogo simbólico, insistência em seguir rotinas, dentre outros (DSM-IV-TR, 2002).

Embora a etiologia do transtorno ainda seja desconhecida, as diferentes abordagens procuram explicações distintas para a manifestação da diversidade dos sintomas (Lampreia, 2004). É assim que a abordagem naturalista, representada pela Teoria da Mente, defende que sujeitos autistas apresentam um déficit cognitivo inato, responsável por todos os sintomas posteriores. Portanto, em se tratando da autoconsciência, a perspectiva da Teoria da Mente argumenta, no caso do autismo, a partir de resultados experimentais, que

indivíduos com autismo podem saber tão pouco sobre suas próprias mentes quanto sobre a mente dos outros. Não é que eles não tenham estados mentais, mas, em um sentido importante, são incapazes de refletir sobre seus estados mentais. Eles não possuem a maquinária cognitiva para representar seus pensamentos e sentimentos como pensamentos e sentimentos. Da mesma maneira, embora sejam capazes de observar o comportamento e expressões emocionais dos outros, são incapazes de fazer sentido de seu comportamento através da atribuição de estados mentais (Frith \& Happé, 1999: 7-8).

Em suma, uma falha no mecanismo subjacente à computação de estados mentais prejudicaria tanto o autoconhecimento como o conhecimento de outras mentes, o que acarretaria prejuízos nas áreas social e da comunicação. No entanto, autistas de alto-funcionamento possuem a habilidade de refletir sobre seus próprios estados mentais e os dos outros, mas parecem fazê-lo através de um lento e difícil processo de aprendizagem; através de um caminho longo e tortuoso (Frith \& Happé, 1999).

Por outro lado, a visão construtivista defende que os comportamentos do desenvolvimento infantil só podem ser desenvolvidos através das interações sociais compartilhadas pelas pessoas. É por isso que Hobson (2002) defende que o prejuízo primário do autismo se encontra no engajamento social com os outros, acarretando vários prejuízos secundários, que são aqueles descritos nas áreas de comunicação e comportamento encontrados no DSM-IV-TR (2002). É devido também à gravidade dos prejuízos sociais que Wing (1988) distingue três tipos de autistas: o isolado, ou seja, aquele que evita o contato social; o passivo, considerado 
aquele que aceita contato social, mas não o inicia; e o bizarro, que interage socialmente de forma peculiar. Isto demonstra que, mesmo que de modos distintos, as interações sociais dos autistas são qualitativamente prejudicadas, o que acarreta graves consequências para o seu desenvolvimento, destacando-se aqui as falhas no aparecimento da autoconsciência.

Em se tratando desta questão, como a abordagem construtivista enfatiza a construção da autoconsciência no desenvolvimento infantil a partir das interações sociais e da linguagem, é possível supor que todo o processo que culmina com o aparecimento da mesma se encontra prejudicado nas crianças autistas. Como os prejuízos nas interações sociais são identificados nestas crianças antes dos dois anos (Adrien et al., 1993; Maestro et al., 2005), é provável que a formação do self emergente e nuclear ocorra de modo diferente nelas, acarretando, consequentemente, falhas na formação do self subjetivo e do self verbal.

A origem destas falhas pode estar naquilo que Hobson (2002) defende como o principal prejuízo encontrado em crianças autistas, que são as falhas na conexão afetiva inata com a sua mãe. Hobson e colaboradores (2006) afirmam que esta falta de conexão afetiva é explicada pelo processo de identificação. Para os autores, o transtorno autista decorre fundamentalmente de falhas no processo de identificação entre os indivíduos. Desta forma, bebês que mais tarde são diagnosticados autistas não respondem às ações e comportamentos dos outros e nem são movidos e afetados pelos sentimentos dos mesmos. Com isso, não conseguem responder e interagir adequadamente às trocas afetivas indispensáveis para o seu desenvolvimento.

Esta teoria encontra respaldo nos prejuízos detectados precocemente em autistas, nos seus dois primeiros anos de vida, antes de receberem o diagnóstico (Adrien et al., 1993; Maestro et al., 2005). Para Hobson (2002), tais prejuízos, como os distúrbios no contato ocular (Adrien et al., 1993; Trevarthen \& Daniel, 2005), déficit na atenção às pessoas (Maestro et al., 2005; Trevarthen \& Daniel, 2005), ausência de sorriso social (Adrien et al., 1993; Trevarthen \& Daniel, 2005), prejuízos nas expressões faciais, gestos apropriados e posturas expressivas (Adrien et al., 1993) e falta de imitação (Trevarthen \& Daniel, 2005), impedem que o bebê participe de experiências de compartilhamento mútuo com as pessoas e se envolva em trocas afetivas recíprocas com elas. Do mesmo modo, seguindo o pensamento de Stern (1992) a respeito do desenvolvimento infantil típico, é possível inferir que os prejuízos no aparecimento destes comportamentos levem a dificuldades severas destas crianças na capacidade de autoagência, como, por exemplo, seus déficits na capacidade de atenção e reciprocidade social, gerando prejuízos na compreensão de suas próprias ações (Maestro et al., 2005; Trevarthen \& Daniel, 2005) e na autoafetividade, devido aos prejuízos no contato ocular e nas expressões 
faciais, gestos apropriados e posturas expressivas (Adrien et al., 1993; Trevarthen \& Daniel, 2005). Além disso, devido a problemas sensoriais que podem exibir, provavelmente elas apresentam também dificuldades na autocoerência, visto que as variações no modo de receber os estímulos sensoriais podem ser prejudiciais para o reconhecimento de um corpo integrado (Baranek et al., 2006), causando, consequentemente, distúrbios na sua auto-história.

Deste modo, estas crianças apresentariam prejuízos severos no desenvolvimento de seu self emergente e nuclear. Consequentemente, as crianças autistas passariam a apresentar dificuldades em se envolver em situações que lhes permitam compartilhar os objetos e os eventos do mundo com as pessoas, comportamento que evidencia o aparecimento do selfsubjetivo. Ao não realizarem isso, elas se tornariam incapazes de se orientar em um mundo repleto de significados compartilháveis onde as pessoas se experimentam como seres diferentes, com distintos modos de sentir, ser e estar em um contexto que é sempre compartilhado com o outro. Dito de outro modo, elas também não conseguiriam desenvolver o seu self subjetivo, cujas falhas ficam evidenciadas pelos prejuízos nos comportamentos de atenção compartilhada ou interatencionalidade (Maestro et al., 2005; Tomasello, 2003) e também naqueles relativos a intersubjetividade e sintonia afetiva (Greenspan \& Wider, 2006; Hobson, 2002). Deste modo, o seu self verbal apresentaria déficits significativos, o que é plenamente justificável através dos danos que estas crianças apresentam no desenvolvimento da fala (Baron-Cohen, Allen \& Gillberg, 1992; Hobson, 2002).

Seguindo este raciocínio, com as dificuldades no relacionar-se afetivamente com o outro, as crianças autistas apresentam prejuízos severos no desenvolvimento do seu selfe dos selves dos outros. Com isso, elas não apresentam o desenvolvimento da autoconsciência, ou seja, um pensamento reflexivo sobre si mesmas e a capacidade para entender que o seu próprio selfé objeto de avaliação e análise tanto para os outros quanto para si mesmas. E evidências significativas dão respaldo a esta visão, como as dificuldades de adolescentes autistas no uso dos pronomes pessoais (Lee \& Hobson, 1994), prejuízos na expressão e descrição de emoções sociais (Hobson, 2002; Hobson et al., 2006) e prejuízos no aparecimento do jogo simbólico (BaronCohen et al., 1992; Williams, Reddy \& Costall, 2001), sendo este considerado um dos principais marcadores para identificar um possível diagnóstico de autismo para crianças com 18 meses de idade (Baron-Cohen et al., 1992).

Por outro lado, contrariando o pensamento anterior e assemelhando-se à Teoria da Mente, Hobson (2002) reconhece que autistas podem apresentar algumas formas de identidade e reconhecimento de self, como serem capazes de remover rouge de sua testa ao se olharem no espelho ou quando se reconhecem 
em fotografias. Além disso, alguns autistas podem utilizar e compreender o uso dos pronomes pessoais em algumas situaçōes restritas (Lee \& Hobson, 1994), podem apresentar algumas formas de emoçôes sociais, como culpa ou embaraço quando não atingem um objetivo específico ou não executam uma atividade com presteza (Hobson et al., 2006), e são capazes de desenvolver alguns tipos de jogos simbólicos que envolvam representações diretas da realidade, como, por exemplo, colocar um copo de brinquedo na boca (Williams et al., 2001).

Para Hobson e colaboradores (2006), a explicação para isto se encontra nas linhas dissociáveis do desenvolvimento das crianças autistas. Dito de outra forma, os autores acreditam que o desenvolvimento do autista apresenta dissociaçōes, ou seja, alguns comportamentos podem ser desenvolvidos sem que haja interferência do engajamento com o outro, como, por exemplo, a capacidade que o autista apresenta de decorar falas de personagens na tv, enquanto outros comportamentos, como a capacidade de responder ao sorriso de alguém, dependem inexoravelmente do contato afetivo com o outro e por isso autistas não os desenvolvem. Assim, os autores defendem que os autistas são capazes de se envolver em relações que estabelecem com o mundo não social, chamadas por eles de $I-I t$ (eu-isto), enquanto as I-Thou (eu-tu), consideradas as relaçôes sociais, se encontram prejudicadas. Devido a isto, os autores afirmam que autistas são capazes de realizar imitações de objetivos diretos, mas não fazem imitações onde precisam se identificar com os sentimentos de outra pessoa para assumir, então, as suas orientações físicas. Também são capazes de apreender as intenções dos outros quando agem com objetivos diretos, mas não apreendem as intençôes dos outros de modo a responder às atitudes afetivas deles. Além disso, são capazes de responder a algumas reações emocionais dos outros, mas não são afetados pelas expressões dos seus sentimentos. Por fim, há ainda um contraste na compreensão de estados mentais dos autistas. Segundo os autores, eles podem apreender alguns estados mentais das pessoas não porque se identificam com elas, mas porque recordam os settings onde os sentimentos das pessoas foram expressos e os aplicam apenas nestas circunstâncias.

Seguindo este pensamento, os autistas apresentariam a capacidade de desenvolver níveis menos complexos dos comportamentos encontrados no desenvolvimento infantil típico, níveis estes que não dependem das interações para serem desenvolvidos. O mesmo é válido considerando-se o aparecimento da autoconsciência, que, mesmo que não se desenvolva plenamente, encontra expressóes mais simples. É por isso que eles usam os pronomes pessoais apenas em situações restritas em que decoram onde estes pronomes foram empregados, utilizando-os apenas em situações semelhantes; apresentam emoções sociais não porque se percebem como alvo de observação e julgamento do outro e assimilem este julgamento para 
se autoavaliarem, mas porque se autoavaliam como vencedores ou fracassados ao desempenharem ou não determinada tarefa com eficácia; e são capazes de jogos simbólicos restritos apenas à sua percepção imediata e não aos significados que podem ser criados a partir do compartilhar com os outros.

Disto decorre que, ainda que diferentemente de crianças com desenvolvimento típico, as autistas conseguem se envolver em determinados tipos de relações. Estas relações permitem-lhes desenvolver algum tipo de distinção entre o seu self e o do outro, embora a autoconsciência reflexiva pareça não se desenvolver. Portanto, o desafio é fazer com que estas crianças se engajem em interações afetivas recíprocas que possam propiciar a emergência de sua autorreflexividade.

Concluindo, segundo a visão construtivista, a identificação parece ser o precursor para o desenvolvimento das relações intersubjetivas entre o recém-nascido e sua mãe. Contudo, ela pode assumir diferentes níveis, passando por identificações iniciais com as expressões corporais e movimentos dos outros até que se chegue a identificaçōes mais subjetivas, nas quais a criança passa a se identificar com os sentimentos, açôes e perspectivas dos outros. Neste processo, tal como salientam Hobson e colaboradores (2006), o desenvolvimento do self apresenta também níveis, assumindo formas iniciais de identidade e autoconhecimento do próprio corpo, através da constituição e diferenciação entre o eu emergente e nuclear e outros, já apresentadas pelo pensamento de Stern (1992), até alcançar níveis mais reflexivos, tais como o self subjetivo, o self verbal e a autoconsciência.

Em se tratando do transtorno autístico, falhas na identificação acarretam prejuízos severos nas interaçôes sociais e na capacidade de os autistas se envolverem nos significados compartilhados pelo seu grupo social através da linguagem, causando um desvio no desenvolvimento dos portadores do transtorno. Este desvio faz com que alguns níveis de desenvolvimento do self possam ser adquiridos, ainda que com limitações, mas impossibilita a emergência da autoconsciência reflexiva. Se isto for verdadeiro, a chave para um melhor atendimento a indivíduos com o transtorno talvez esteja na questão da identificação. Fazê-los se envolver e se engajar em trocas afetivas, portanto, parece ser o ponto crucial para os programas de intervenção com sujeitos autistas (Fiore-Correia, 2005).

\section{Conclusão}

O propósito do presente ensaio foi refletir acerca das falhas na emergência da autoconsciência no autismo. Para tanto, vimos os dois enfoques principais - cognitivista e construtivista - e procuramos, para ambos, fundamentos nas áre- 
as da filosofia e da neurociência. Por adotarmos uma perspectiva construtivista, procuramos analisar mais especificamente os processos envolvidos na emergência da autoconsciência no desenvolvimento típico e os problemas apresentados no âmbito do autismo.

No nosso entender, o problema com a perspectiva cognitivista não é, pura e simplesmente, sua defesa do inatismo, já que qualquer perspectiva, mesmo a mais social, deve admitir uma dimensão inata para o desenvolvimento humano. O problema consiste em esta perspectiva adotar uma posição determinista e não considerar a importância de se conceber o desenvolvimento como envolvendo uma articulação entre o inato e o social. Em outras palavras, uma perspectiva construtivista também requer a admissão de uma base inata, observada na capacidade de o bebê humano ser sensível e responsivo às emoçôes de outro ser humano, assim como de ele próprio ser emocionalmente expressivo. Mas apenas isso não é suficiente para dar conta de qualquer ponto do desenvolvimento. É preciso também considerar que diferentes formas de interação social poderão levar a diferentes resultados de desenvolvimento mesmo que a base inata tenha sido a mesma.

Em suma, uma perspectiva construtivista concebe o desenvolvimento humano como uma construção social a partir de uma base inata. A lógica, no que se refere ao caso do autismo, consiste em argumentar que, dados certos prejuízos nas capacidades inatas, o bebê se torna incapaz de se engajar em interaçôes sociais que irão promover o seu desenvolvimento. Daí o desvio em seu desenvolvimento geral e, mais especificamente, na sua capacidade de autoconsciência.

Mas vejamos, então, o que entendemos por autoconsciência, no contexto deste ensaio. Parece haver um consenso, entre diferentes autores vistos, de que a autoconsciência humana envolve uma capacidade de autorreflexividade. Hobson e colaboradores (2006) concebem a autoconsciência como a capacidade de autorreflexividade; uma habilidade exclusiva da espécie humana de refletir acerca de seus próprios sentimentos e ações. Damásio (2000) define a consciência reflexiva como a capacidade de pensar sobre suas próprias experiências conscientes por si mesmas, sendo ela o ápice da hierarquia, e exclusivamente humana. E a Teoria da Mente também se refere à capacidade de autorreflexividade quando trata da autoconsciência.

Dado esse consenso, vejamos em que medida a filosofia e as neurociências podem oferecer fundamentos para o argumento construtivista das falhas na emergência da autoconsciência no autismo. No campo da filosofia, uma perspectiva construtivista/pragmática, tal como a de Wittgenstein (1958), não concebe a autoconsciência como uma capacidade inata envolvendo um conhecimento direto de nosso mundo interior, nem nossas verbalizações na primeira pessoa como descrições 
de eventos internos, como advoga a visão cartesiana. A autoconsciência envolve, na verdade, um jogo de linguagem adquirido através de práticas sociais.

No campo das neurociências, Damásio $(1995 ; 2000)$ propõe uma teoria de construção do self segundo a qual a base das capacidades de consciência e self deve ser encontrada na integração de emoções primárias e secundárias. E segundo a qual a plena autoconsciência humana se dá na e pela linguagem. Neste caso, uma falha na integração dos diferentes tipos de emoções e uma falha no desenvolvimento da linguagem podem resultar em uma autoconsciência precária, como no caso do autismo. Mas isto não significa que não haja outras formas de consciência e self (Winograd, Sollero-de-Campos \& Drummond, 2008). Damásio (2000) se refere a um self central, anterior ao self autobiográfico, distribuído por todo o corpo e envolvendo a experiência imediata. Ele também se refere a um self autobiográfico pré-linguístico, além de uma autoconsciência não-verbal. Isto é, ele concebe o self como uma estruturação em progressivo afastamento das restrições biológicas desde os estados corporais do self central até o self autobiográfico plenamente linguístico, o que possibilita a existência de processos de desenvolvimento singulares e atípicos, dados os "diferentes graus de vinculação à natureza e à criação [...] do self central e do self autobiográfico" (Damásio, 2000: 445-446).

Como visto, segundo uma perspectiva construtivista do desenvolvimento típico, a autoconsciência se desenvolve a partir de um processo que depende, inicialmente, das trocas afetivas entre o bebê e sua mãe. Primeiro em um nível físico, até poder alcançar um nível reflexivo linguístico. Os processos interacionais de base afetiva possibilitam o aparecimento inicial de um self corporal e, posteriormente, de um self subjetivo e verbal, dando condições para o surgimento da autoconsciência humana plena. De acordo com Stern (1992), nos primeiros sete meses de vida os contornos que separam o self do bebê de outros selves estão relacionados aos seus aspectos corporais. A partir desse momento, esses contornos passam a abarcar experiências ligadas a desejos, necessidades e intenções das pessoas, constituindo a distinção entre um self e outros selves subjetivos e, posteriormente, o self verbal. Para Hobson (2002), a partir dos nove meses, a identificação da criança com os comportamentos do adulto relacionados a objetos e eventos no mundo permite que ela passe a considerar que os outros apresentam perspectivas e estados mentais próprios diferentes dos dela. É quando surge uma nova consciência de si e dos outros no desenvolvimento infantil típico. Contudo, a criança ainda não é capaz de refletir sobre um comportamento ou sobre como se sentiu em determinada situação. Ela ainda não possui a autoconsciência, que só começa a aparecer por volta do segundo ano de vida. Em suma, no desenvolvimento típico a autoconsciência se desenvolve a partir de um nível pré-reflexivo no qual as experiências corporais de integração 
permitem um desenvolvimento incipiente de self até um nível reflexivo através de formas mais complexas de percepção do self permitindo a autoconsciência.

No caso do autismo, devido a falhas na identificação afetiva, todo o processo de interaçôes sociais que culmina com o aparecimento da autoconsciência está prejudicado. Consequentemente, ela também o estará. Foram identificados, em crianças autistas, vários prejuízos na interação social antes dos dois anos de idade que acarretariam prejuízos no desenvolvimento dos self emergente, self nuclear, self subjetivo e self verbal e, desta forma, na autoconsciência, sendo a dificuldade no uso de pronomes pessoais uma das evidências mais claras. Porém alguns autistas podem apresentar algumas formas de identidade e reconhecimento de self, assim como algumas formas de emoções sociais, e utilizar e compreender o uso de pronomes pessoais. Podem também realizar imitações, apreender as intençõos e alguns estados mentais dos outros, mas sempre em situações imediatas. Contudo, essas crianças autistas desenvolvem essas habilidades de forma embrionária e por outros meios que não a identificação afetiva, evidenciando dissociações em seu desenvolvimento. Em suma, alguns autistas podem chegar a apresentar expressões mais simples de autoconsciência, desenvolvidas por meio de outros mecanismos, mas não à autoconsciência reflexiva.

Embora o ensaio tenha sido uma tentativa inicial de levantar apontamentos relevantes relativos à importância da autoconsciência para o desenvolvimento humano e como isto pode se tornar imprescindível para o tratamento de sujeitos autistas, novos estudos são imprescindíveis para uma melhor compreensão do fenômeno no desenvolvimento humano típico e de pacientes acometidos com transtornos graves como o autismo.

\section{REFERÊNCIAS}

Adrien, J., Lenoir, P., Martineau, J., Perrot, A. Hameury, L., Larmande, C. \& Sauvage, D. (1993). Blind ratings of early symptoms of autism based upon family home movies. Journal of the American Academy of Child and Adolescent Psychiatry, 32(3), 617-626.

Baron-Cohen, S., Allen, J. \& Gillberg, C. (1992). Can autism be detected at 18 months? The needle, the haystack and the CHAT. British Journal of Psychiatry, 161, 839-843. Baranek, G. T., David, F. J., Poe, M. D., Stone, W. L. \& Watson, L. R. (2006). Sensory experiences questionnaire: discriminating sensory features in young children with autism, developmental delays and typical development. Journal of Child Psychology and Psychiatry, 47(6), 591-601. 
Brazelton, T. \& Cramer, B. (1990). The earliest relationship: parents, infants and the drama of early attachment. Cambridge, Mass: Merloyd Lawrence.

DSM-IV-TR (2002). Manual diagnóstico e estatístico de transtornos mentais. Porto Alegre: Artes Médicas.

Damásio, A. (1995). O erro de Descartes. Lisboa: Europa-América.

Damásio, A. (2000). O mistério da consciência. São Paulo: Companhia das Letras.

Descartes, R. (1637/1996). Discurso do método. São Paulo: Martins Fontes.

Edelman, G. (1992). Bright air, brilliant fire. New York: Basic Books.

Fiore-Correia, O. B. (2005). A aplicabilidade de um programa de intervenção precoce em crianças com possivvel risco autístico. Dissertação de Mestrado. Curso de Pós-graduação em Psicologia Clínica, Pontifícia Universidade Católica do Rio de Janeiro, RJ.

Frith, U. \& Happé, F. (1999). Theory of mind and self-consciousness: what is it like to be autistic? Mind \& Language, 14(1), 1-22.

Greenspan, S. \& Wider, S. (2006). Engaging autism - using the floortime approach to help children relate, communicate and think. Cambridge: Da Capo Lifelong Books.

Hacker, P. M. S. (2007). Human nature: the categorial framework. Oxford: Blackwell Publishing.

Hobson, R. P. (2002). The cradle of thought. London: MacMillan.

Hobson, R. P., Chidambi, G., Lee, A. \& Meyer, J. (2006). Foundations for self-awareness: an exploration through autism. Monographs of the Society for Research in Child Development, 71(2), vii-188.

Lampreia, C. (1992). As propostas anti-mentalistas no desenvolvimento cognitivo: uma discussão de seus limites. Tese de Doutorado. Curso de Pós-graduação em Psicologia Clínica, Pontifícia Universidade Católica do Rio de Janeiro, RJ.

Lampreia, C. (2004). Os enfoques cognitivista e desenvolvimentista no autismo: uma análise preliminar. Psicologia Reflexão e Crítica, 17(1), 111-120.

Lampreia, C. (2008) O processo de desenvolvimento rumo ao símbolo: uma perspectiva pragmática. Arquivos Brasileiros de Psicologia, 60(2), 117-128.

Lee, A. \& Hobson, R. P. (1994). I, you, me and autism: an experimental study. Journal of Autism and Developmental Disorders, 24(2), 155-176.

Lee, A. \& Hobson, R. P. (1998). On developing self-concepts, a controlled study. Journal of Child Psychology and Psychiatry, 39(8), 1131-1144.

Leslie, A. (1987). Pretense and representation: the origin of "Theory of Mind". Psychological Review, 94(4), 412-426.

Maestro, S., Muratori, F., Cavallaro, M., Pecini, C., Cesari, A., Paziente, A., Apicella, F., Stern, D., Golse, B. \& Palacio-Espasa, F. (2005). How young children treat objects and people: an empirical study of the first year of life in autism. Child Psychiatry and Human Development, 35(4), 383-396. 
Meltzoff, A. \& Moore, M. (1998). Infant intersubjectivity: broadening the dialogue to include imitation, identity and intention. In: S. Bråten (org.). Intersubjective communication and emotion in early ontogeny (pp. 47-62). Cambridge: Cambridge University Press.

Penrose, R. (1999). The Emperor's new mind. Oxford: Oxford University Press.

Sollero-de-Campos, F. (2000). Um pequeno mapa das desleituras: psicanálise e neurociência. Cadernos do IPUB, VI(18), 133-144.

Sollero-de-Campos, F., Winograd, M. \& Landeira-Fernandez, J. (2007). Psicanálise e neurociência: condiçóes, experimentações e clínica. In: J. Landeira-Fernandez \& M. T. A. Silva (orgs.). Interseçôes entre neurociência e psicologia (pp. 25-42). São Paulo: Medbook.

Stern, D. (1992). O mundo interpessoal do bebê. Uma visão a partir da psicanálise e da psicologia do desenvolvimento. Porto Alegre: Artes Médicas.

Tomasello, M. (2003). Origens culturais da aquisição do conhecimento humano. São Paulo: Martins Fontes.

Trevarthen, C. \& Daniel, S. (2005). Disorganized rhythm and synchrony: Early signs of autism and Rett syndrome. Brain \& Development, 27, S25-S34.

Williams, E., Reddy, V. \& Costall, A. (2001). Taking a closer look at functional play in children with autism. Journal of Autism and Developmental Disorders, 31(1), 67-77.

Wing, L. (1988). The continuum of autistic characteristics. In: E. Schopler \& G. B. Mesibov (orgs.). Diagnosis and Assessment in Autism (pp. 91-110). New York: Plenum Press.

Winograd, M., Sollero-de-Campos, F. \& Drummond, C. (2008). O atendimento psicológico a pacientes neurológicos. Mal-estar e subjetividade, 8(1), 139-170.

Wittgenstein, L. (1958). Philosophical investigations. Oxford: Basil Blackwell.

\section{Notas}

1 Ao longo do artigo, utilizaremos o termo cognitivista ou naturalista para nos referir ao cognitivismo naturalista que defende o papel do inatismo como determinante para o desenvolvimento da cognição e linguagem humanas. Por outro lado, ao utilizarmos o termo construtivista, estamos tratando do construtivismo social, que articula o inato e o social na construção do desenvolvimento humano.

2 Uma representação primária descreve um aspecto particular da realidade, enquanto uma metarrepresentação, ou representação de segunda ordem, representa a atitude de um agente para uma descrição de um aspecto particular da realidade (Frith \& Happé, 1999).

3 Chama-se de mãe a todas as pessoas consideradas os principais cuidadores do bebê, o que significa dizer que o termo pode se referir tanto à mãe biológica quanto a todos os responsáveis pelo cuidado do mesmo. 
4 Stern (1992) não se refere ao conceito de autoconsciência em sua teoria, ainda que fale sobre o eu como objeto de reflexão para o indivíduo. Contudo, enfatiza o termo self, se referindo à capacidade de integração das experiências sensoriais e afetivas de um indivíduo que o separa e o distingue dos outros indivíduos. Nesta discussão, o desenvolvimento do selfé um precursor para o aparecimento da autoconsciência, visto que, para que um indivíduo possa alcançar uma capacidade reflexiva sobre si mesmo, ele necessita perceber-se separado dos demais.

5 É interessante observar que Damásio (2000) propõe o conceito de sentimentos de fundo, que estão conectados aos humores, aos estados afetivos e à consciência central. São indicadores corporais sutis que nos ajudam a "definir nosso estado mental e dão cor à nossa vida" (Damásio, 2000: 362): por exemplo, a postura corporal, a prosódia, o tom de voz, a gesticulação são indicadores para nós, e para os outros, de sentimentos de fadiga, energia, bem-estar, malestar, tensão, harmonia, desequilíbrio. Damásio considera tais sentimentos de fundo muito semelhantes aos afetos de vitalidade propostos por Stern.

Recebido em 23 de junho de 2009 Aceito para publicação em 01 de junho de 2010 